14,13

\title{
Микрофазовое разделение в имидсилоксановом сополимере
}

\author{
(C) Д.В. Новиков ${ }^{1}$, В.М. Светличный르 А.А. Мартыненков ${ }^{2}$ \\ ${ }^{1}$ Санкт-Петербургский государственный лесотехнический университет им. С.М. Кирова, \\ Санкт-Петербург, Россия \\ ${ }^{2}$ Институт высокомолекулярных соединений РАН, \\ Санкт-Петербург, Россия \\ E-mail: dvnovikov65@mail.ru, valsvet@hq.macro.ru
}

Поступила в Редакцию 12 фревраля 2019 г.

В окончательной редакции 12 февраля 2019 г.

Принята к публикации 19 марта 2019 г.

По данным электронной микроскопии проведен сравнительный анализ микронеоднородной структуры поверхности пленок аморфного ароматического полиэфиримида - поли $\left\{4,4^{\prime}\right.$-бис $\left[\left(4^{\prime \prime}\right.\right.$-N-фенокси)дифенилсульфон]имида 1, 3-бис (3', 4-дикарбоксифенокси)бензола $\}$ (PEI) - и имидсилоксанового блочного сополимера (PSI), содержащего блоки звеньев PEI и блоки диметилсилоксановых звеньев. Показано, что в пленке PSI, по сравнению с PEI, возрастают анизотропия, дальний порядок и корреляционная длина флуктуаций плотности. Образец PSI имеет несимметричную биаксиальную текстуру поверхности в отличие от PEI, для которого характерна аксиальная текстура. По направлению осей текстуры PSI в микронном масштабе наблюдаются периодические осцилляции плотности. Полученные результаты свидетельствуют о микрофазовом разделении в пленке PSI за счет пространственно ориентированных контактных взаимодействий между блоками диметилсилоксановых звеньев.

Ключевые слова: тонкие пленки, полимеры, размерные эффекты, электронная микроскопия.

DOI: $10.21883 /$ FTT.2019.07.47857.378

\section{1. Введение}

В блок-сополимерах с термодинамически несовместимыми блоками звеньев имеет место микрофазовое разделение, которое сопровождается формированием периодической надмолекулярной микроструктуры материала [1]. Создание в блок-сополимерах упорядоченных структурных образований субмикронного и микронного размера представляет особый интерес с точки зрения представлений о самоорганизации макромолекул [2].

Отдельно следует выделить группу термостойких имидсилоксановых блок-сополимеров (PSI), содержащих в макромолекулярной цепи протяженные последовательности диметилсилоксановых звеньев и получаемые на основе ароматических полиэфиримидов, например, поли $\left\{4,4^{\prime}\right.$ - бис [(4"' - N - фенокси)дифенилсульфон] имида 1, 3-бис (3', 4-дикарбоксифенокси)бензола $\}$ (PEI) $[3,4]$.

В работе [5] при изучении вязкоупругих характеристик ряда силоксансодержащих полиимидов были получены данные, указывающие на термодинамическую несовместимость ароматического и диметилсилоксанового фрагментов цепи. Такая несовместимость обусловливает возможность микрофазового разделения в образцах за счет сегрегации блоков диметилсилоксановых звеньев. Позднее в работе [6] методом протонной магнитной релаксации была изучена локальная динамика метильных групп в пленках образцов PSI и было установлено, что диметилсилоксановые звенья склонны к образованию ассоциативных структур с пониженной подвижностью метильных групп.

Микросегрегация неорганических участков цепей макромолекул может приводить к мезоморфизму полимеров ряда органосиликсанов [6,7]. В этой связи следует ожидать усиления структурной анизотропии, формирования выраженной текстуры полимерных пленок, а также возникновения дальнего порядка чередования плотности надмолекулярных образований (флуктуаций плотности) по направлениям осей текстуры. Однако в настоящее время отсутствуют конкретные данные о трансформации топологической структуры пленок при переходе от PEI к PSI.

В работе [8] с применением просвечивающей электронной микроскопии (ТЕМ) была изучена топология флуктуаций плотности на поверхности аморфных [9] пленок гибкоцепного PEI. Образцы формировались из растворов PEI в N-метил-2-пирролидоне (МП). Было показано, что в пленках может наблюдаться псевдофазовое разделение, при котором возникает субмикронный дальний порядок пространственного чередования флуктуаций плотности с периодом $L \sim 0.25 \mu \mathrm{m}$. Использование термина „псевдофазовое“ объясняется тем, что в данном случае кластеры „фаз“ находятся в аморфном состоянии, имеют одинаковый состав, но отличаются плотностью упаковки макромолекул. Важно отметить, что пространственная модуляция флуктуаций плотности имела место в случае пленок, сформированных из концентрированных растворов PEI. При 
этом концентрация растворов существенно превышала пороговое значение $c^{*} \sim 14$ mass.\%, соответствующее перекрыванию макромолекулярных клубков [8]. Известно, что в растворах полиамидокислот и полиимидов [10] проявляются сильные межмолекулярные взаимодействия, способствующие образованию ассоциатов или кластеров макромолекул, корреляционная длина которых существенно превышает гидродинамический радиус клубка. Кластерная структура растворов, в свою очередь, предопределяет формирование в пленках неоднородной структуры физической сетки макромолекул с флуктуациями плотности субмикронного масштаба [8].

В настоящей работе использованы образцы пленок PEI и термически имидизованного форполимера PSI. Пленки были получены из 20 mass.\% растворов полимеров в МП. Выбор данного концентрационного режима формирования полимерных пленок позволил провести сравнительный структурный анализ образцов в субмикронном и микронном диапазонах масштаба с использованием традиционной методики ТЕМ. Цель работы обнаружение в образце PSI микрофазового разделения, обусловленного дополнительным контактным взаимодействием блоков диметилсилоксановых звеньев.

\section{2. Объекты и методы исследования}

Образцы полиимидов были получены в лаборатории синтеза высокотермостойких полимеров Института высокомолекулярных соединений РАН. Полимерные пленки толщиной 20-25 $\mathrm{m}$ формировались на стеклянной подложке из 20 mass.\% растворов PEI и форполимера PSI (полиамидокислоты) в МП. Пленки прогревались в режиме ступенчатого повышения температуры до $553 \mathrm{~K}$. При этом в случае PEI происходило удаление следов растворителя, а в случае форполимера PSI имела место термическая имидизация образца. Степень имидизации полиимидов была $\sim 95 \%$ [4].

Сополимер PSI отвечал химической формуле:
Верхний фрагмент формулы представляет собой элементарное звено PEI, индексы в формуле соответствуют значениям $m=18, p=q$ [4]. По данным седиментационно-диффузионного анализа [11] молекулярная масса PEI составляла $\sim 6 \cdot 10^{4}$ Да.

Для анализа топологической структуры поверхности пленок была использована методика декорирования золотом „химических меток“ хемосорбированного брома. Данная методика, применимая к аморфным и мезоморфным полиимидам [8,9], основана на предварительной активации поверхности за счет образования активных центров - молекулярных комплексов брома с электронодонорными функциональными группами макромолекул. В дальнейшем активные центры служат потенциальными зародышами наночастиц золота при его вакуумном термическом напылении на исследуемую поверхность, а плотность распределения наночастиц флуктуирует подобно плотности упаковки макромолекул. Препарирование образцов для ТЕМ осуществлялось путем предварительной активации „воздушной“ поверхности пленок жидким бромом по методике [8] с последующим вакуумным (при давлении $10^{-3} \mathrm{~Pa}$ ) термическим напылением золота. Наночастицы золота отделялись от поверхности с помощью опорной угольной реплики и изучались в просвечивающем электронном микроскопе EMV100L. Двумерные изображения декорированной поверхности подвергались компьютерной оцифровке и включали при этом не менее 5000 частиц.

Для выявления дальнего порядка и расчета корреляционной длины $\zeta$ флуктуаций плотности использовалась так называемая „крупнозернистая“ радиальная функция $g(R)$ распределения декорирующих наночастиц. Функция $g(R)$ рассчитывалась при сканировании двумерного изображения поверхности образцов с шагом $\delta$, превышающим наиболее вероятное расстояние $r$ между частицами [12]. Величина $r$ составляла $\sim 20 \mathrm{~nm}$ для образца PEI и $\sim 50 \mathrm{~nm}$ для PSI.

Индикатрисы плотности $\rho$ распределения частиц получены при усреднении по прямоугольникам $2 r \times \xi$ с центром в частицах и изменении угла $\theta$ ориентации прямоугольников [12]. Периодичность чередования плотно-<smiles>CCN1C(=O)c2ccc(Oc3cccc(Oc4ccc5c(c4)C(=O)N(c4ccc(Oc6ccc(S(=O)(=O)Oc7ccc(Oc8ccc(C)cc8)cc7)cc6)cc4)C5=O)c3)cc2C1=O</smiles><smiles>CCCCCN1C(=O)c2ccc(Oc3cccc(Oc4ccc5c(c4)C(=O)N(CC)C5=O)c3)cc2C1=O</smiles> 
сти по направлениям осей текстуры образцов изучалась с использованием соответствующих функций $g(R)$.

\section{3. Результаты и их обсуждение}

Декорирующие наночастицы золота (рис. 1) имеют довольно широкое распределение по размеру $(4-100 \mathrm{~nm})$, свидетельствующее о неоднородном энергетическом микрорельефе поверхности полимерных пленок. Скопления мелких наночастиц отображают флуктуации повышенной плотности упаковки макромолекул. Крупные частицы золота соответствуют менее плотным областям поверхности [8]. Доля пространства [8], приходящаяся на плотные агрегаты макромолекул, для обоих образцов близка к 0.3 .
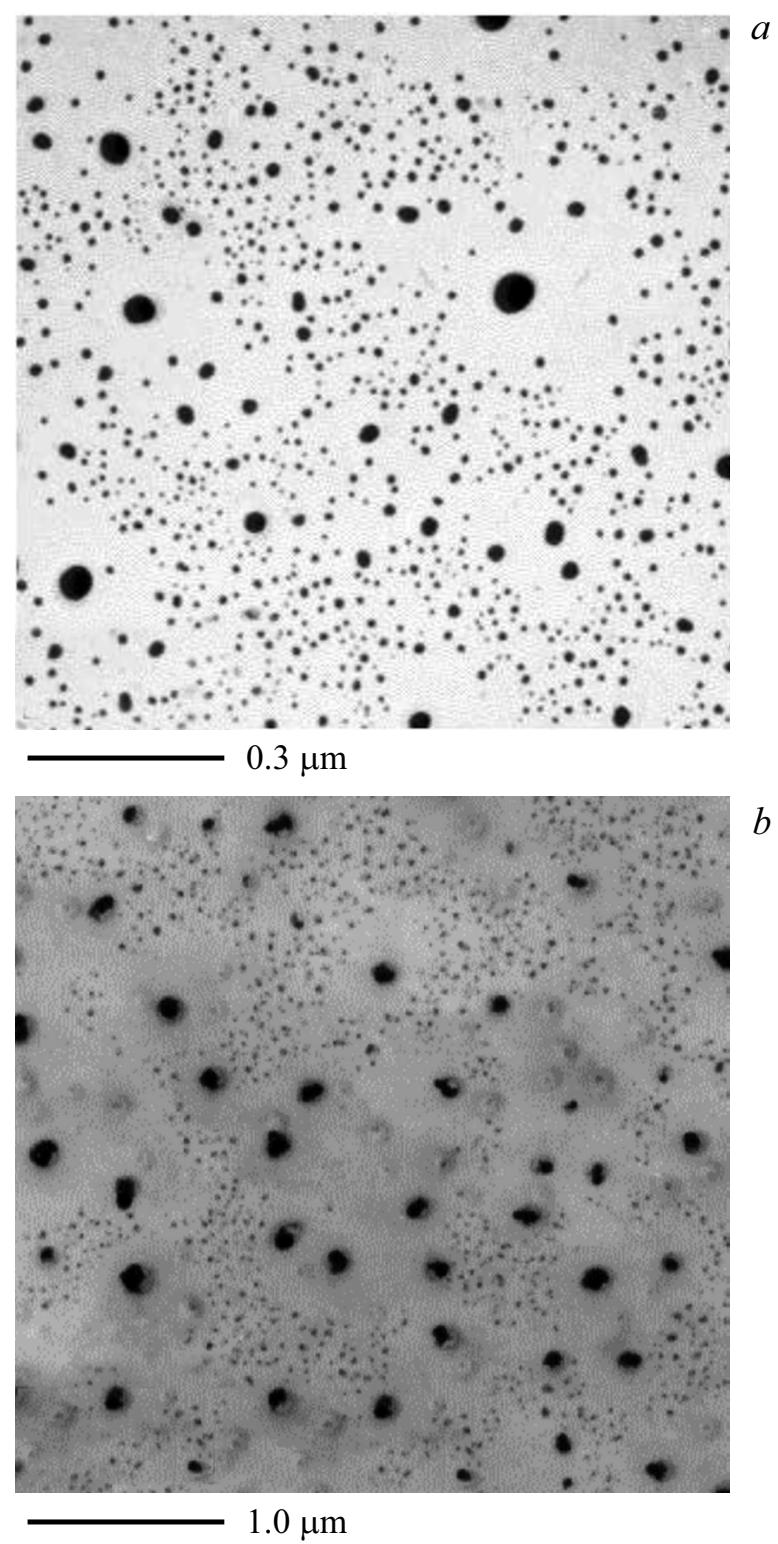

Рис. 1. Электронные микрофотографии декорированной золотом поверхности пленок PEI $(a)$ и PSI $(b)$.
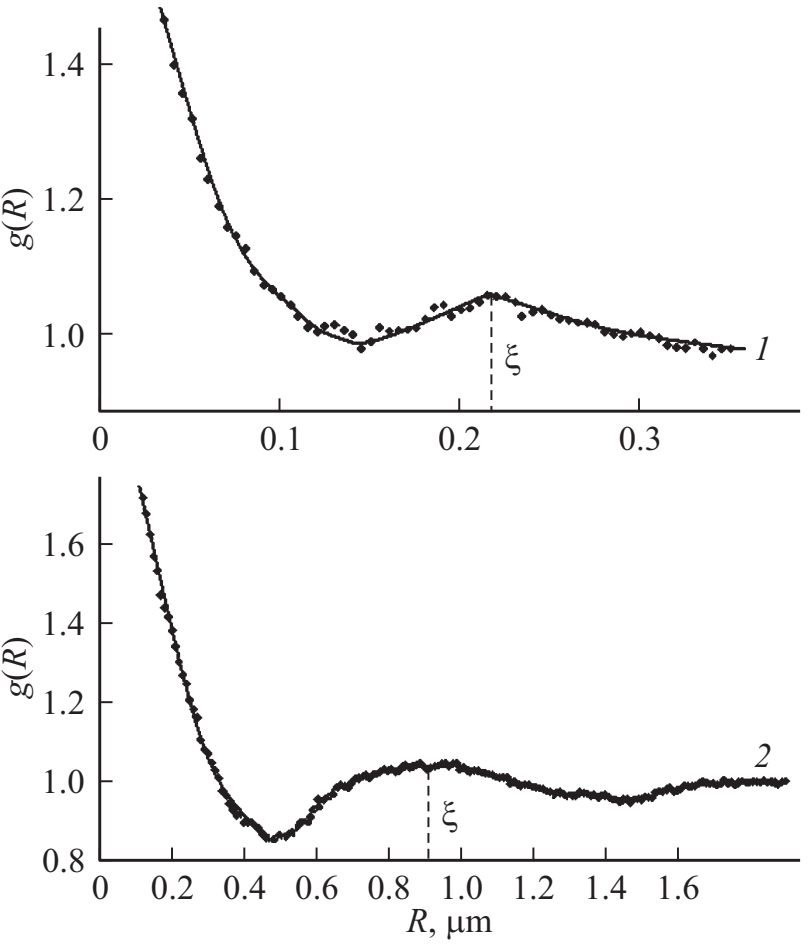

Рис. 2. Радиальные функции $g(R)$ распределения плотности скоплений наночастиц золота на поверхности пленок PEI (1) и PSI (2).

На поверхности полимерных пленок наблюдается дальний порядок скоплений наночастиц золота. Возникновение дальнего порядка сопутствует фазовому или псевдофазовому [12] разделению в полимерных материалах. Периодичность локальной плотности распределения частиц обнаруживается при построении функций $g(R)$ с шагом $\delta=40-60 \mathrm{~nm}$ (рис. 2). Период соответствует положению максимума функций $g(R)$ и равен корреляционной длине $\xi$. В образце PSI (рис. 2, кривая 2), по сравнению с PEI (рис. 2, кривая 1), возрастает дальний порядок чередования флуктуаций плотности (величина максимума функций $g(R)$ ), а величина $\xi$ увеличивается в четыре раза, что свидетельствует об усилении фазового разделения.

На рис. 3 представлены индикатрисы относительной локальной плотности $\rho$ распределения наночастиц золота на поверхности образцов. Полученные угловые зависимости $\rho(\theta)$ позволяют определить характер текстуры поверхности пленок. Известно [13], что в пленках ароматических полиимидов часто возникает оптическая анизотропия, которая может являться следствием различных причин: ориентационных эффектов, образования мезофаз, внутренних механических напряжений, кристаллизации полиимида.

В исследуемых образцах наблюдается анизотропия плотности. Отличие между PEI и PSI состоит в том, что в первом случае (рис. 3, кривая 1) имеет место аксиальная текстура, а во втором (рис. 3, кривая 2) - 

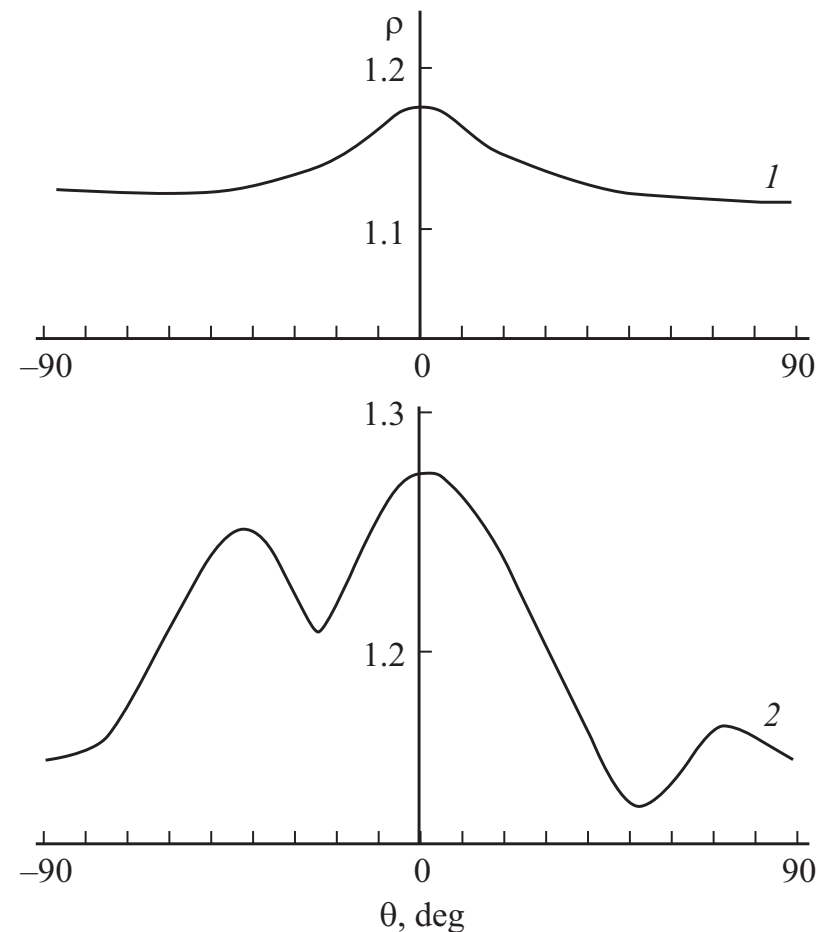

Pис. 3. Индикатрисы относительной (по отношению к средней по поверхности) плотности $\rho$ распределения наночастиц золота на поверхности пленок PEI (1) и PSI (2). Ось ординат $(\theta=0$ градусов $)$ соответствует оси текстуры - направлению с максимальным значением $\rho$.

несимметричная биаксиальная, соответствующая двум направлениям с повышенной локальной плотностью частиц. Угол $\theta$ между этими направлениями равен $40^{\circ}$. Отметим, что в пленках некоторых аморфных полиимидов может наблюдаться квазиизотропная симметричная биаксиальная текстура, для которой $\theta=90^{\circ}$ [12]. В случае же PSI пространственное распределение плотности принципиально анизотропно.

На поверхности пленки PEI локальные плотности распределения частиц вдоль и поперек единственной оси текстуры отличаются не более чем на 4\% (рис. 3 , кривая 1). Такая слабовыраженная анизотропия плотности подтверждается данными работы [14], в которой было зафиксировано спонтанное двойное лучепреломление в пленках PEI. Обнаруженный эффект объяснялся возникновением слабого ориентационного порядка фрагментов макромолекул вблизи поверхности пленок. Малая степень ориентационного порядка типична [14] для пленок, полученных из растворов гибкоцепных полимеров.

Поверхность пленки PSI характеризуется выраженной несимметричной биаксиальной текстурой, при этом плотности вдоль и поперек главной оси текстуры (оси с максимальной локальной плотностью частиц) отличаются более чем на $10 \%$ (рис. 3 , кривая 2). В этой связи можно говорить об общем росте анизотропии при переходе от PEI к PSI. В работе [12] при сравнении
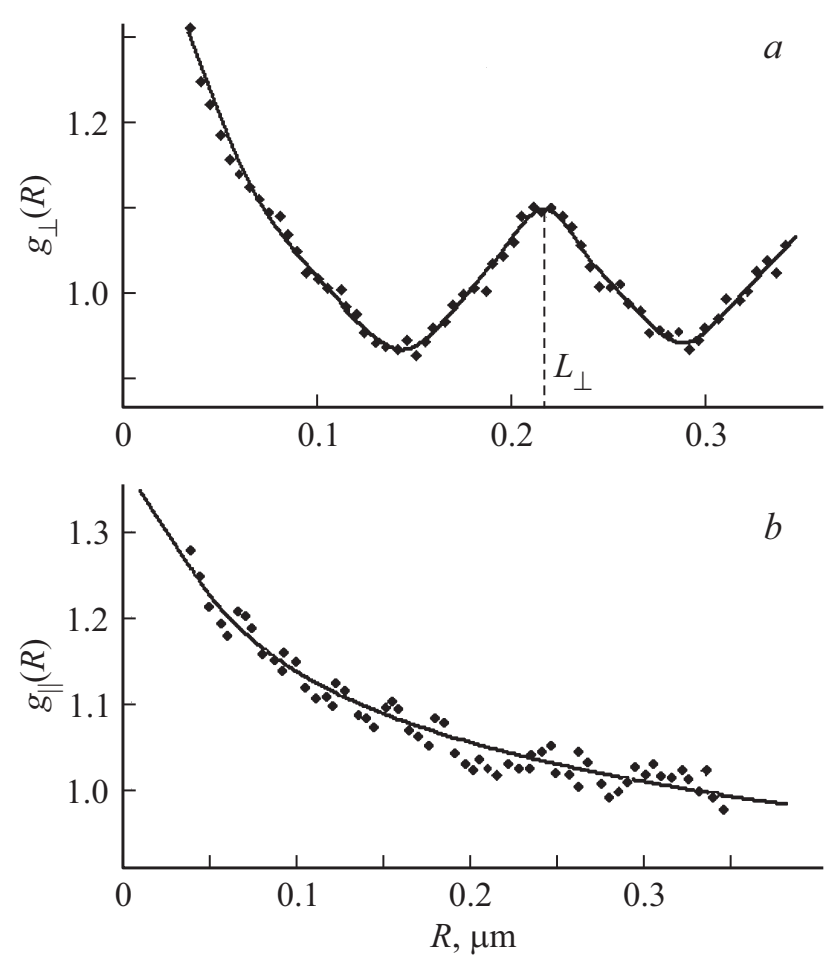

Рис. 4. Радиальные функции распределения плотности, построенные поперек $(a)$ и вдоль $(b)$ оси аксиальной текстуры на поверхности пленки PEI.
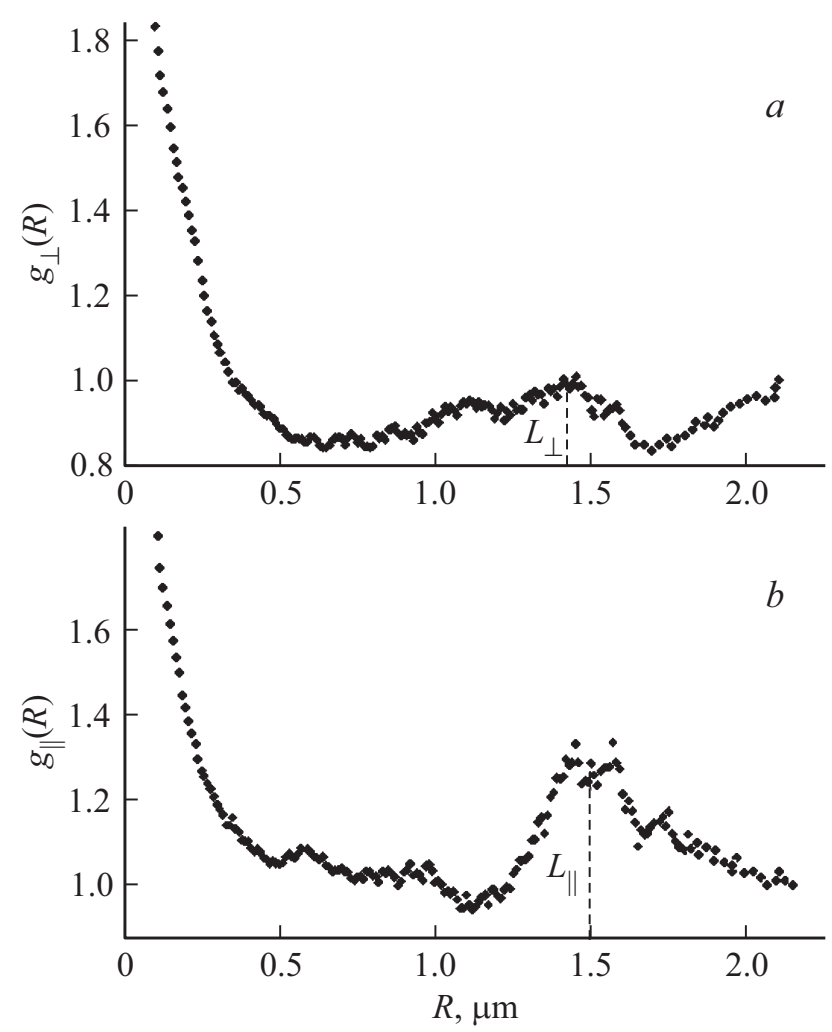

Рис. 5. Радиальные функции распределения плотности, построенные поперек $(a)$ и вдоль $(b)$ первой оси биаксиальной текстуры на поверхности пленки PSI. Ось текстуры соответствует максимальной локальной плотности распределения частиц. 


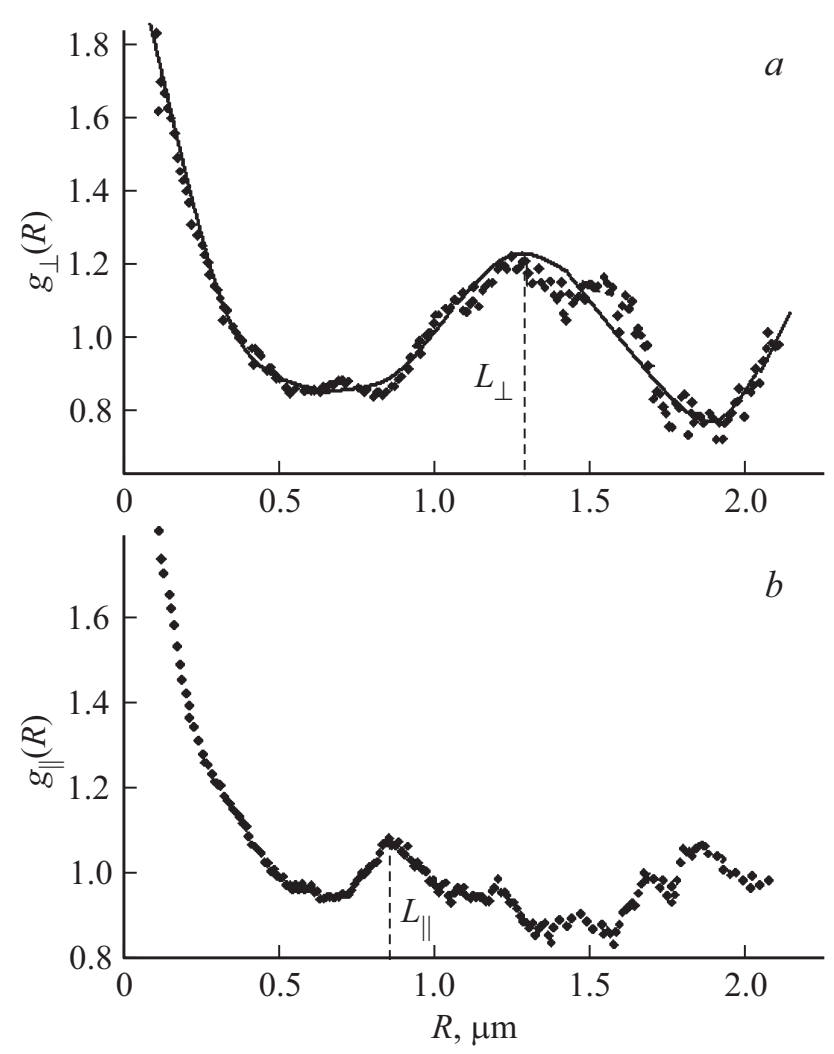

Рис. 6. Радиальные функции распределения плотности, построенные поперек $(a)$ и вдоль $(b)$ второй оси биаксиальной текстуры на поверхности пленки PSI.

пленок аморфного полиимида и адамантансодержащего сополимида также был зафиксирован рост анизотропии плотности. Этот эффект объяснялся контактным взаимодействием адамантиленовых фрагментов, статистически распределенных вдоль цепи [12].

Несимметричная биаксиальная текстура образца PSI указывает, что в пленке PSI, по сравнению с PEI, формируется особое направление с повышенной локальной плотностью распределения частиц. Это направление можно связать с ориентацией блоков диметилсилоксановых звеньев при их контактном взаимодействии между собой. В работе [15] было установлено, что высокая гибкость силоксановой цепи и межмолекулярное „специфическое“ взаимодействие алкильных боковых групп способны приводить к самоорганизации макромолекул полиорганосилоксанов. Следствием самоорганизации может быть образование упорядоченных мезоморфных фаз [15].

На рис. 4, 5 и 6 приведены функции $g_{\perp}(R)$ и $g_{\|}(R)$, рассчитанные соответственно поперек и вдоль осей текстуры исследуемых образцов.

На поверхности пленки PEI наблюдается периодичность флуктуаций плотности поперек оси текстуры (рис. 4, $a$ ), а вдоль оси такая периодичность отсутствует (рис. $4, b)$. При этом корреляционная функция $g_{\|}(R)$ вдоль оси текстуры спадает по степенному закону
$g_{\|}(R) \propto R^{-0.1}$, характерному для фрактальных объектов с фрактальной размерностью $D \sim 1.9$. Значение $D \sim 1.9$ соответствует так называемому внутреннему перколяционному кластеру на двумерной решетке [16]. Отметим, что фрактальные свойства присущи сильно неоднородным средам, в качестве которых выступают, в частности, аморфные полимеры [17]. В случае PEI фрактальные свойства поверхности пленки проявляются по оси текстуры полимера.

Образец PSI характеризуется периодическим распределением плотности поперек (период $L_{\perp}$ ) и вдоль осей (период $L_{\|}$) биаксиальной текстуры. Для оси с максимальной локальной плотностью частиц (рис. 5) периоды $L_{\perp}$ и $L_{\|}$практически совпадают и превышают среднюю корреляционную длину $\xi$. Для другой оси (рис. 6) выполняется условие $\left(L_{\|}+L_{\perp}\right) / 2 \approx \xi$. Периодические осцилляции плотности вдоль и поперек осей текстуры приводят к росту среднего дальнего порядка в пленке PSI по сравнению с PEI.

\section{4. Заключение}

Данные ТЕМ указывают на микрофазовое разделение в пленке PSI и согласуются с известными представлениями о сегрегации блоков диметилсилоксановых звеньев при их контактном взаимодействии между собой. Концепция ориентированной микросегрегации неорганических фрагментов макромолекул PSI подтверждается формированием в образце особого направления с локальными флуктуациями повышенной плотности. Это направление сосуществует с направлением преимущественной ориентации ароматических фрагментов PSI (PEI). Указанные направления обусловливают несимметричную биаксиальную текстуру образца.

Рост анизотропии, дальнего порядка и корреляционной длины флуктуаций плотности в образце PSI по сравнению с PEI, а также формирование периодических осцилляций локальной плотности по осям биаксиальной текстуры PSI могут свидетельствовать о мезоморфизме блочного сополимера.

\section{Конфликт интересов}

Авторы заявляют, что у них нет конфликта интересов.

\section{Список литературы}

[1] A.-V. Ruzette, L. Leibler. Nature Mater. № 4, 19 (2005).

[2] P.G. Khalatur, A.R. Khokhlov. Polymer 59, 74 (2014).

[3] В.М. Светличный, Е.В. Архипова, В.М. Денисов, А.И. Кольцов, В.М. Копылов, В.О. Рейхсфельд, В.М. Светличная. Высокомолекуляр. соединения А 32, 2075 (1990).

[4] В.М. Светличный. Термопластичные полиимиды для композиционных материалов. Докт. дис., СПб (2007). 290 с. 
[5] Е.А. Сидорович, А.А. Мартыненков, А.Е. Трофимов, В.М. Светличный, О.А. Незабудкина, В.В. Кудрявцев. Высокомолекуляр. соединения А 40, 1979 (1998).

[6] Ю.А. Зайцева, В.А. Шевелев, А.А. Мартыненков, В.М. Светличный, В.В. Кудрявцев. Высокомолекуляр. соединения А 44, 36 (2002).

[7] Yu.K. Godovsky, V.S. Papkov. Adv. Polym. Sci. 88, 129 (1989).

[8] Д.В. Новиков, А.Н. Красовский, В.Н. Филиппов, Т.Е. Суханова, В.М. Светличный. ЖПХ 76, 1160 (2003).

[9] Д.В. Новиков, Т.Е. Суханова, В.М. Светличный, И.В. Гофман, А.И. Григорьев, А.Л. Диденко, Т.А. Маричева, В.В. Кудрявцев. Высокомолекуляр. соединения А 43, 655 (2001).

[10] О.В. Каллистов, В.В. Кривобоков, Н.А. Калинина, И.Г. Силинская, Ю.И. Кутузов, А.В. Сидорович. Высокомолекуляр. соединения А 27, 968 (1985).

[11] О.В. Окатова, А.Л. Диденко, В.М. Светличный, Г.М. Павлов. Высокомолекуляр. соединения 58А, 15 (2016).

[12] Д.В. Новиков. ФТТ 59, 1006 (2017).

[13] М.И. Бессонов, М.М. Котон, В.В. Кудрявцев, Л.А. Лайус. Полиимиды - класс термостойких полимеров. Наука, Л. (1983). 328 c.

[14] Г.М. Павлов, А.С. Губарев, Г.Ф. Колбина, И.П. Коломиец, А.Л. Диденко, В.М. Светличный. Высокомолекуляр. соединения А 59, 150 (2017).

[15] В.Г. Васильев. Специфические взаимодействия и особенности реологических свойств силоксанов. Докт. дис., М. (2008). 312 c.

[16] Е. Федер. Фракталы. Мир, М. (1991). 254 с. [J. Feder. Fractals. Plenum Press, N. Y., London (1988). 260 p.].

[17] Г.М. Бартенев, С.Я. Френкель. Физика полимеров. Химия, Л. (1990). 432 c.

Редактор Т.Н. Василевская 